\title{
Eva Palkovičová
}

Universidad Comenio Bratislava

\section{El factor tiempo en dos ediciones eslovacas de la novela El río oscuro de Alfredo Varela}

Palabras clave: obra original, traducción, factor temporal, reedición

\section{Introducción}

Es bien sabido que los textos escritos envejecen, debido a la falta de sincronía entre el momento de la escritura y el de la lectura. Es una característica propia tanto de los textos originales como de sus posibles traducciones. Si nos referimos a la traducción, un texto, surgido de una manera «natural» tendrá una forma totalmente «artificial» en otra lengua y otra cultura, en la mayoría de los casos en un tiempo histórico diferente. Después, cada nueva traducción se realiza para acercar la obra original a los lectores desde una nueva perspectiva traductológica, con el fin de «sobrepasar las diferencias temporales, o históricas, que pueden afectar a aspectos lingüísticos pero también a aspectos estéticos e incluso ideológicos» (Hurtado Albir, 2010). Por tanto queda claro que el traductor desempeña un papel importante como agente de esta nueva perspectiva. Todas las traducciones existentes de una obra original son fruto de la actividad creadora de su autor y reflejan la situación personal y profesional del traductor durante todas las fases del proceso traductológico. Se dice que las traducciones están sometidas a un mayor y más rápido envejecimiento que las obras originales y, en algunas ocasiones, más que los propios traductores. Sin embargo, no es muy frecuente que un traductor tenga la posibilidad de revisar, corregir, actualizar su traducción y preparar una nueva edición.

Según Anton Popovič, el original es un acto único e irrepetible, mientras que las traducciones de este primer acto creativo pueden ser múltiples (Popovič, 1975: 184). Cada nueva traducción entra en algún contacto con la anterior, 
le sirve como cierto «espejo», la reevalúa desde una perspectiva espacial y temporal nueva y diferente.

Sin embargo, en la historia de las traducciones del español al eslovaco no hay muchas obras que hayan sido traducidas más de una vez. Hay muchas razones que justifican esta situación. Según nuestra opinión, esto se debe también al hecho de que la historia de la hispanística eslovaca prácticamente arranca sólo en los años cincuenta del siglo XX. Además, el grupo reducido de traductores literarios (o «artísticos» según la terminología eslovaca) ha tenido que llenar tantas lagunas en el ámbito de las obras traducidas del español al eslovaco que no ha podido «invertir tiempo y energía» en nuevas versiones de las traducciones ya existentes. Como hemos podido comprobar, hasta hoy no se ha publicado ni una sola obra de la narrativa española o hispanoamericana en una nueva traducción al eslovaco. Ni siquiera Don Quijote.

Tampoco hay muchas traducciones que se hayan reeditado varias veces. La novela El río oscuro (1943) del autor argentino Alfredo Varela (1914-1984) se publicó en eslovaco por primera vez en 1951 y fue la primera traducción en forma de libro del actual doyen de la hispanística eslovaca, Vladimír Oleríny (1921). En 1968, aparece la segunda edición de su traducción, en la que son patentes considerables retoques.

El objetivo de este artículo es comparar detalladamente los dos textos, analizar el género de los cambios y tratar de caracterizar la estrategia traductora que empujó al traductor a re-escribir su propia traducción. Puesto que se trata de dos re-ediciones de la misma traducción, publicadas con una distancia de 17 años, nos interesa examinar la influencia de los aspectos temporales respecto a la traducción, edición, revisión y re-edición del libro.

Cada obra literaria tiene su propia vida, que «se realiza» por medio de diferentes formas de presentación (lectura, reseña, crítica, dramatización, traducción...) y recepción. El tiempo condiciona considerablemente la «vida» del texto literario por medio de las circunstancias en las cuales fue creado, publicado y «realizado» (Bílik 1994: 81).

De este modo, consideramos como factores fundamentales el tiempo individual (la situación personal y profesional del autor/traductor en el momento de la creación de su obra) y el tiempo colectivo (el carácter del contexto histórico, socio-cultural y traductológico) dentro del cual «pulsan» diferentes «tiempos individuales» (Bílik, 2008: 11). 


\section{Contexto de la traducción y de su primera edición (1951)}

En la historia de la literatura eslovaca (checoslovaca) de posguerra, el año 1951 da comienzo a una década considerada como la primera fase de la época del proclamado método creativo del realismo socialista, que aclama al nuevo héroe que gracias a su trabajo construye una nueva sociedad. El tema del colectivo de los trabajadores y de la patria que después del victorioso Febrero del 1948 avanza hacia un futuro feliz, se convirtió en uno de los postulados constantes para la mayor parte de la producción literaria checa y eslovaca de esas décadas. Las novelas «industriales», «construidas» por los «ingenieros del alma humana», se convirtieron en uno de los fenómenos más exigidos en esos años del estalinismo duro y violento (Bílik, 1994: 44).

La gran popularidad de la novela del autor argentino en los países socialistas (la obra fue traducida en total a más de quince idiomas) se debe a varias razones: a su «mensaje» actual en aquel entonces, a su carácter exótico y también a su novedad temática. No hay que olvidar, que hasta 1951 no fueron traducidos al eslovaco ni los cuentos «de la selva» de Horacio Quiroga, ni las novelas «ejemplares» de la tierra. Además, esta novela «post-telúrica», publicada en 1943 cumplía con muchos de los postulados «socialistas» de la literatura de los años cincuenta: describía la explotación de los mensúes en Misiones y transmitía la imagen del mundo capitalista como la de un mundo injusto y cruel, en el seno del que nace una nueva fuerza: el proletariado organizado. A la vez, en la terminología de entonces, «abría ventanas» hacia el mundo exótico de la selva latinoamericana. Sin embargo, quizá no sea exagerado decir que esta novela, además de ser política e ideológicamente correcta, captó mucho más el interés de nuestros lectores por su ambiente, atmósfera y modo de narrar que las obras «industriales» de aquella época, escritas por algunos autores eslovacos (o checos).

La novela resultó atractiva también por su estructura y por su estilo, que fueron elementos innovadores respecto a las pocas novelas hispanoamericanas traducidas y publicadas anteriormente ${ }^{1}$. Varela combina el relato cronológico de la historia del protagonista con las descripciones «cinematográficas» de la selva personificada e intercala la crónica de los pasos dados por los blancos para dominar el mundo del Alto Paraná. Como

1 Las primeras novelas hispanoamericanas traducidas al eslovaco: Hugo Wast: El camino de lamas (Cesta lám, 1948), Manuel Gálvez: Miércoles santo (Defilé hriechu, 1948) y Alfredo Gravina: Perdido en su noche (Noc už pominula, 1948). Todas fueron traducidas por Tibor Kobáň (autodidacta y gran aficionado del español y otras lenguas románicas). 
se escribe también en la Presentación de la edición argentina de 1985, Varela «mucho antes que otros escritores argentinos y latinoamericanos fracturó el relato, a la manera de Faulkner, para que la visión del lector pudiera ir llegando desde ángulos diferentes» (en Varela, 1985: 5). También cabe señalar que la línea poética de la novela le pudo resultar muy familiar al lector eslovaco gracias a la narrativa de la «prosa lirizante» eslovaca (lyrizovaná próza) de entreguerras.

Además, el autor -encarcelado varias veces durante el gobierno del general Perón- pasó cierto tiempo como exiliado también en Checoslovaquia y después de su visita en 1949 a la Unión Soviética, Polonia y Checoslovaquia fue considerado como el camarada que lucha «contra el imperialismo, por la paz y progreso» (Amado, 1951: 312).

También conviene señalar que el libro ya había sido publicado anteriormente en checo en dos ediciones en 1949 y 1951, por lo que la editorial eslovaca ya tenía cierto «punto de referencia» ${ }^{2}$.

En cuanto al traductor de la novela, Vladimír Oleríny, en 1951 era un joven diplomático de treinta años recién llegado de Buenos Aires. En el ambiente político e ideológico de los años cincuenta, el territorio de la traducción literaria presentaba para él cierto refugio con la posibilidad de aprovechar el español y sus conocimientos del contexto político y cultural hispanoamericano. Como ya hemos dicho, El río oscuro de Varela es su primera traducción publicada en forma de libro. No es de extrañar que eligiese un libro tan popular en Argentina, y que le resultase familiar en cuanto al ambiente y al tema. Por tanto, en cuanto a la «distancia» temporal y contextual entre el original y el texto traducido, la novela de Varela de 1943 y la traducción de Oleríny de 1951 fueron obras casi «contemporáneas».

Aunque Vladímir Oleríny gracias a su estancia en Argentina fue uno de los pocos privilegiados que disponían de diccionarios de la lengua española, enciclopedias, diccionarios de hispanoamericanismos, etc., no pudo contar con diccionarios relevantes de español-eslovaco, tampoco con diccionarios académicos de la lengua eslovaca.

Desde el punto de vista traductológico, esta primera traducción le sirvió como un manual de la traducción. Como confesó el propio traductor, solamente las

2 El libro de Varela se publicó en checo por primera vez en 1949 en la traducción de Kamil Uhlír. Como escribe Miroslav Uličný, la novela pertenece «a la ola de novelas sociales traducidas al checo. [...] Por su veracidad [...] y quizá también por su acento social la novela volvió a editarse en checo en 1951 y una vez más en 1962» (Uličný, 2005: 80). 
advertencias y correcciones de sus colegas y editores le hicieron comprender en qué «consiste» la traducción literaria.

Finalmente, una vista pragmática: la primera edición de El río oscuro publicada en la editorial «Dukla» ${ }^{3}$ tuvo una tirada de 5.000 ejemplares. En la cubierta, además del nombre del autor y del título, aparece sólo la figura en negro de un hombre con una guitarra. El texto de la novela está acompañado por un epílogo de Jorge Amado, firmado y fechado en 1951 en la Casa de los Escritores Checoslovacos, situada en el castillo checo de Dobříšs. Este detalle demuestra los contactos de los escritores checoslovacos con los autores de orientación izquierdista y los viajes de éstos por los países socialistas. En el epílogo, que tiene el carácter de un panfleto político, Amado destaca las actividades de Alfredo Varela y la lucha de los escritores e intelectuales latinoamericanos por la paz y por la vida semejante a la del pueblo soviético: «feliz, satisfactoria, alegre y bonita» (Amado, 1951: 312).

En cuanto a la evaluación crítica, hemos encontrado sólo una reseña de la novela de Varela, en la revista eslovaca Slovenské pobl'ady en 1951. Su autor, Ján Povrazník, además de resumir el argumento, subraya la estructura novedosa de la novela y advierte que se trata de una «traducción bonita de Vlado Oleríny preparada muy cuidadosamente por la editorial Dukla».

\section{Contexto de la segunda edición (1968)}

La primavera del año 1968, cuando aparece la reedición de la traducción de Vladimír Oleríny, es un momento emblemático en la historia de las naciones checa y eslovaca. Entre otras cosas, representa el símbolo de la esperanza y posible liberación de la vida sociopolítica y cultural, es «tiempo de deshielo», derrotado después por la invasión soviética en agosto de 1968.

De ahí que la segunda edición de la traducción eslovaca de El río oscuro aparezca en un contexto social, político, cultural -incluso traductológicodiferente, aunque todavía marcado por la ideología comunista. Sin embargo, en la literatura eslovaca aparecen ya muchas obras que desenmascaran el esquematismo de la producción literaria del realismo socialista. Por eso podemos suponer que en el contexto del año $1968 \mathrm{ni}$ el tema, ni el aspecto ideológico de la novela de Varela eran tan atractivos para los lectores eslovacos como en 1951. Además, nuestro público lector ya disponía de las primeras

3 Dukla es el nombre de un desfiladero en las montañas del Este de Eslovaquia, lugar de una célebre batalla entre las tropas soviéticas y las tropas nazis en 1944. 
traducciones de las obras escritas por los representantes de la nueva novela hispanoamericana, por ejemplo el ensayo Problemas de la novela latinoamericana de Alejo Carpentier publicado en la revista Slovenské pobl'ady (1965), El túnel de Ernesto Sabato (Tunel samoty, 1965), algunos cuentos de Julio Cortázar (1965) o la novela El papa verde de Miguel Ángel Asturias (Zelený pápež, 1965), todo traducido al eslovaco por Vladimír Oleríny.

En este contexto, la re-edición de la novela de Varela puede parecer anacrónica, o, por el contrario, política e ideológicamente muy conveniente para el plan de edición de la editorial especializada en la «literatura política», que tenía la obligación de incluir en su plan de ediciones una cantidad determinada de obras progresistas.

En cuanto al traductor Vladimír Oleríny, en 1968 ya era un traductor experimentado, acaso el miembro más destacado de la comunidad de los hispanistas eslovacos. Sin embargo, su carrera desde 1951 hasta 1968 no fue directa ni fácil. A pesar de haber sido fundador de la hispanística en Eslovaquia y primer profesor eslovaco de literatura española e hispanoamericana en la Facultad de Filosofía y Letras en Bratislava, a finales de los años cincuenta perdió, como muchos otros intelectuales «la confianza» del partido comunista y tuvo que pasar algunos años como obrero en una empresa industrial. Sólo después llegó a ser secretario de la Unión de los Escritores Eslovacos y más tarde empezó a trabajar en el Instituto de la Literatura Universal de la Academia Eslovaca de Ciencias.

Durante esos 17 años, tradujo más de una veintena de obras (poesía, narrativa, teatro) de la literatura española e hispanoamericana al eslovaco y escribió como era costumbre- un sinfín de epílogos, críticas, reseñas y artículos sobre la literatura y cultura de los países hispanos.

Esta edición se publicó en la misma editorial, sin embargo, rebautizada desde el año 1953 como «Editorial eslovaca de la literatura política».

La edición del 1968 se publicó en una tirada de 7.000 ejemplares, esta vez sin el epílogo, solamente en el texto de la solapa se cita de nuevo a Jorge Amado, quien advierte, que El río oscuro de Varela es una obra «convincente y conmovedora, penetrada de una profunda poesía. Es una novela con una técnica sumamente interesante y enriquecedora. Su autor tiene todas las calidades del escritor excelente». Observamos que esta vez se subraya más el aspecto literario que el aspecto ideológico de la novela. 
La cubierta de la segunda edición es sumamente interesante. Esta vez se trata de un collage compuesto de fragmentos de fotografías en color de una joven moderna, atractiva, con uñas largas y pintadas, con los labios rojos, muy marcada por la estética y la moda de los años sesenta. Sin embargo, el diseño, muy apropiado para el año 1968, no tiene nada que ver ni con el argumento de la novela (la historia de los recogedores pobres de mate en la selva amazónica), ni con ninguno/ninguna de sus protagonistas. Con tal imagen de fondo, el título de la obra alude más a una historia de amor turbio, trágico y apasionado.

\section{$4 \quad$ Una vista traductológica}

Desde el punto de vista traductológico, la novela de Valera presenta un verdadero reto para cada traductor. La narración realista y cronológica de la historia del protagonista Ramón, las descripciones poéticas de la naturaleza, el texto documental de la crónica del descubrimiento y de la explotación del Alto Paraná y, además, fragmentos de diferentes poemas, diarios y artículos periodísticos que aparecen en forma de cita en el inicio de cada capítulo, forman una estructura fragmentada muy peculiar con muchas alusiones intertextuales y exigen del traductor constantes cambios de registro lingüístico.

Cada género y tipo de textos utilizados en esta novela se nutre de recursos literarios diferentes y el traductor debe utilizar la estrategia traductológica adecuada para mantener no solamente el carácter total de la obra, sino también el carácter típico de cada uno de los niveles estilísticos: de la narración realista (coloquialismos, dialectismos, elementos específicos relacionados con el trabajo y la vida de los recolectores de mate, terminología de flora y fauna de la selva, etc.), de las descripciones de la naturaleza (lenguaje metafórico de los pasajes poéticos, sintaxis «no estándard» con oraciones largas y complicadas), del texto sobre la conquista, documental y a la vez metafórico, lleno de cuestiones retóricas y exclamaciones y, finalmente, el estilo de cada una de las citas introductorias.

Como ya hemos mencionado, en la edición de la traducción del año 1968 notamos considerables retoques. El análisis comparativo de los dos textos presentó cambios significativos en el plano morfológico-sintáctico, lexical y estilístico. En algunos se percibe una influencia de carácter ideológico.

Para ilustrarlo, vamos a exponer pars pro toto algunos ejemplos, que se refieren a cada uno de los fenómenos mencionados. 


\subsection{Interferencias morfológico- sintácticas}

\begin{tabular}{|l|l|l|}
\hline & p. 44 & $\begin{array}{l}\text { Moviéndose a tientas en la penumbra, los dos hombres acertaron con el } \\
\text { picaporte y penetraron en la pieza suavizando su ruido. }\end{array}$ \\
\hline 1951 & p. 57 & $\begin{array}{l}\text { Habkajúc v polotme, dvaja mužskí obratne zdvihli závoru a opatrne } \\
\text { našlapujúc, vošli do izby. }\end{array}$ \\
\hline 1968 & p. 45 & Dvaja mužskí v pološere nahabkali kluku a obozretne vošli do izby. \\
\hline
\end{tabular}

La oración de la edición de 1951 está traducida literalmente, casi palabra por palabra, y mantiene también la estructura morfológico-sintáctica española: el orden de las palabras es una copia de la frase original, los dos verbos se mantienen en gerundio. La versión del año 1968 ya cumple con todos los requisitos de la sintaxis eslovaca: la frase empieza con el sujeto, los gerundios, que con el tiempo adquirieron en eslovaco un matiz de estilo culto, científico o administrativo, son sustituidos por dos verbos en pretérito perfecto. La frase es más fluida, clara y coloquial. Además, el traductor cambió la versión «obratne zdvihli závoru», es decir «levantaron el cerrojo con habilidad» por la expresión coloquial y dialectal «nahabkali kl'uku», es decir «manosearon el picaporte». Es interesante que hoy ya las dos expresiones eslovacas resultan anacrónicas.

\begin{tabular}{|l|l|l|}
\hline & p. 46 & Entonces, sin que nadie dijera una palabra, se pusieron en marcha. \\
\hline 1951 & p. 61 & Potom, bez toho, žeby im bol ktosi čo len slovo povedal, kone sa pohly. \\
\hline 1968 & p. 48 & Potom sa kone sami pohli, hoci im nikto nepovedal ani slovo. \\
\hline
\end{tabular}

La traducción de esta frase muestra una transposición literal, palabra por palabra, de la estructura de la frase española. La frase de la segunda edición está elaborada con más libertad morfológico-sintáctica y tiene el carácter correcto de una frase eslovaca.

\subsection{Lenguaje coloquial}

\begin{tabular}{|l|l|l|}
\hline & p. 13 & Yentonces meta chupar y vivir bien. \\
\hline 1951 & p. 18 & A potom si budete len popíjat' a dobre žit'. \\
\hline 1968 & p. 15 & Potom si dáte do nosa a budete si žit' ako králi. \\
\hline
\end{tabular}




\begin{tabular}{|l|l|l|}
\hline & p. 20 & Lo van a pasar lindo. \\
\hline 1951 & p. 20 & Budete mat' dobré časy. \\
\hline 1968 & p. 17 & Budete sa mat' král'ovsky. \\
\hline
\end{tabular}

\begin{tabular}{|l|l|l|}
\hline & p. 15 & $\begin{array}{l}\text {... ladeándose cada vez que las alpargatas desflechadas chocaban con el } \\
\text { abundante pedrerío. }\end{array}$ \\
\hline 1951 & p. 20 & $\begin{array}{l}\text {... ked' sodraté plátené papuče narazily na kamene, ktorých bolo po } \\
\text { ceste vel'ké množstvo. }\end{array}$ \\
\hline 1968 & p. 17 & $\begin{array}{l}\text {... ked'zodraté plátené papuče narazili na kamene, ktorých bolo po } \\
\text { ceste ako maku. }\end{array}$ \\
\hline
\end{tabular}

Aquí podemos notar diferentes grados de transposición del lenguaje coloquial. En la primera edición el traductor transpone las expresiones coloquiales neutrales españolas con las expresiones eslovacas traducidas literalmente (vivir bien/dobre žit'; abundante/vel'ké množstvo). En la segunda edición, para dar fuerza expresiva al texto, las sustituye por los fraseologismos eslovacos: «žit' ako králi», es decir «vivir como reyes»; «ako maku», es decir «como granitos de amapola». Así, el texto adquiere un matiz más coloquial, es notable una clara orientación hacia la naturalización del texto meta.

\subsection{Toponímicos, nombres propios}

\begin{tabular}{|l|l|l|}
\hline & p. 13 & ... por las Misiones Argentinas... \\
\hline 1951 & p. 17 & $\ldots$... v provinciách Misiones argentinas... \\
\hline 1968 & p. 15 & ...v argentínskych provinciách Misiones... \\
\hline
\end{tabular}

\begin{tabular}{|l|l|l|}
\hline & p. 8 & ... a los montes chaqueños \\
\hline 1951 & p. 10 & ... do čakeñských lesov \\
\hline 1968 & p. 10 & ... do pralesov v Gran Chacu \\
\hline
\end{tabular}

\begin{tabular}{|l|l|l|}
\hline & p. 89 & Han llegado de tierras diferentes. Eúscaros y germanos... \\
\hline 1951 & p. 117 & Prišli z rozličných krajín. Euskarovia a Nemci \\
\hline 1968 & p. 91 & Prišli z rozličných krajín. Baskovia, Nemci... \\
\hline
\end{tabular}

Es interesante observar cómo traduce Oleríny las denominaciones toponímicas. En 1951 deja la mayoría de las expresiones en la forma española, no las transcribe, considera (erróneamente) el adjetivo como parte de la unidad léxica 
(Misiones argentinas), aunque podemos suponer que conocía el territorio de referencia por su propia experiencia. En la segunda edición aparece como topónimo solamente «Misiones».

En la segunda frase el traductor transcribe el adjetivo (chaqueños) con la ortografía eslovaca, sin embargo, en la edición de 1968 opta por la forma más clara para el lector eslovaco y pone «do pralesov v Gran Chacu», es decir «a la selva del Gran Chaco». Se percibe una tendencia hacía una transcripción más exacta y ya estandardizada de los elementos geográficos.

Algo similar ocurre en el tercer ejemplo, cuando el traductor transcribe a los «eúscaros» primero como «Euskarovia», utilizando una palabra desconocida en eslovaco. En la segunda edición ya aparece la forma correcta y usual, es decir «Baskovia».

\subsection{Referencias culturales}

\begin{tabular}{|l|l|l|}
\hline & p. 9 & Era un rancho amplio y bajo, de chorizo. \\
\hline 1951 & p. 12 & Chatrč, pokrytá bravčovými kožami... \\
\hline 1968 & p. 11 & Chatrč, steny mala zo slamy obhádzanej hlinou... \\
\hline
\end{tabular}

\begin{tabular}{|l|l|l|}
\hline & p. 24 & $\begin{array}{l}\text {... de ninguna manera quisieron abandonar sus nuevos ponchitos } \\
\text { colorados }\end{array}$ \\
\hline 1951 & p. 33 & $\begin{array}{l}\text {... nechceli sa ani za svet odlúčit' od svojich nových červených ponchos } \\
\text { (+ nota de traductor al pie de la página) }\end{array}$ \\
\hline 1968 & p. 26 & $\begin{array}{l}\text {... ani za svet sa nechceli rozlúčit' s novými červenými pončami (+ nota } \\
\text { de traductor al pie de la página) }\end{array}$ \\
\hline
\end{tabular}

Sin lugar a dudas, la comprensión y traducción correctas de las referencias contextuales e histórico-culturales, sobre todo los «sin equivalente» en la lengua meta, presentan uno de los problemas más complejos. Conviene señalar, que en el texto original aparecen muchas notas a pie de página, en las cuales el propio autor explica las expresiones dialectales o las «traduce» al español. Además, algunas ediciones argentinas de El río oscuro contienen el vocabulario de las palabras guaraníes y portuguesas, problema del que los editores fueron conscientes. Las ediciones eslovacas no disponían del vocabulario que hubiera podido facilitar mucho el trabajo al lector y también al traductor.

Como podemos ver en los ejemplos expuestos, en 1951 Oleríny no encontró un equivalente adecuado para la referencia cultural «rancho de chorizo»y optó 
por la solución confusa «pokrytá bravčovými kožami», es decir «un rancho cubierto con cueros de cerdo». Sin embargo, en 1968 opta por la explicación interna y pone «steny mala zo slamy obhádzanej hlinou», es decir «tenía las paredes de argamasa de paja y barro». Como en Eslovaquia había también casas de este tipo, su solución nos parece acertada y lógica.

Es muy interesante la transcripción de las denominaciones como «poncho»o «sombrero», que hoy forman parte del léxico eslovaco y no presentan ningún problema. En 1951, Oleríny mantiene la forma española en nominativo de plural «ponchos» (aunque la frase eslovaca exige el caso acusativo) y añade una amplia nota del traductor a pie de página, explicando de qué tipo de prenda se trata. En 1968 ya opta por la forma transcrita y declina correctamente. En cuanto a «sombrero», en las dos ediciones usa sorprendentemente la denominación neutral eslovaca «klobúk», con lo cual se pierde el matiz de «lo otro» en el texto meta, aunque la expresión «sombrero» aparece en todas las novelas hispanoamericanas traducidas al eslovaco antes de 1951.

\subsection{Actualización ideológica}

\begin{tabular}{|l|l|l|}
\hline & p. 215 & Así peleó con las tropas de Prestes... (sin nota) \\
\hline 1951 & p. 279 & $\begin{array}{l}\text { bojoval s Prestesovými oddielmi (+ nota: Vodca brazílskeho ludu, } \\
\text { Carlos Luis Prestes. (Pozn. prekl.) }\end{array}$ \\
\hline 1968 & p. 218 & $\begin{array}{l}\text { bojoval v Prestesových oddieloch (+ nota: Ide o oddiely, organizované } \\
\text { legendárnym brazílskym revolucionárom-komunistom Carlosom } \\
\text { Ruizom Prestesom. (Pozn. prekl.) }\end{array}$ \\
\hline
\end{tabular}

\begin{tabular}{|l|l|l|}
\hline & p. 230 & $\begin{array}{l}\text { Su camino de espinas ha de tener en lo sucesivo una luz: la del farol de } \\
\text { ese humilde rancho del Sindicato Obrero... }\end{array}$ \\
\hline 1951 & p. 299 & $\begin{array}{l}\text { Na jeho tŕnistej ceste ho bude viest' jedno svetlo: svetlo lampy } \\
\text { skromnej budovy robotníckeho odborového združenia... }\end{array}$ \\
\hline 1968 & p. 233 & $\begin{array}{l}\text { Na tŕnistej ceste mu d'alej svietilo jediné svetlo: svetlo lampy nad } \\
\text { vchodom do skromnej budovy robotníckeho odborového združenia... }\end{array}$ \\
\hline
\end{tabular}

\begin{tabular}{|l|l|l|}
\hline & p. 235 & $\begin{array}{l}\text { Pero él no se dio cuenta, y cuando quisieron mirar de nuevo ya había } \\
\text { desaparecido en otra vuelta del río, Paraná abajo, dejando como una } \\
\text { estela su grito de victoria. }\end{array}$ \\
\hline 1951 & p. 305 & $\begin{array}{l}\text {... zanechávajúc za sebou, st'a ligotajúcu sa hviezdu, svoj vítazný } \\
\text { pokrik. }\end{array}$ \\
\hline 1968 & p. 236 & Ako žiarivá hviezda sa niesol za ním jeho vítazný pokrik. \\
\hline
\end{tabular}


En los ejemplos expuestos podemos ver una tendencia muy discreta hacia la versión ideológicamente correcta y «clara», bastante evidente en las dos ediciones, aunque de forma diferente. Veamos el primer ejemplo: la versión eslovaca de 1951 es literal, aunque un poco confusa, la podemos comprender como «peleó al lado de Prestes», pero también «peleó contra Prestes». En la versión de 1968 ya la posición de Ramón está clara, leemos «v Prestesových oddieloch», es decir «en las tropas de Prestes». Las notas del traductor resultan también interesantes. En 1951 Oleríny explica que se trata del «líder del pueblo brasileño, Carlos Luis Prestes». En 1968 amplia su nota añadiendo que se trata «de las tropas organizadas por el legendario revolucionario-comunista brasileño Carlos Ruiz Prestes». Lo curioso es que su nombre correcto es Luís Carlos Prestes.

En el segundo ejemplo, en 1951 Oleríny traduce la expresión perifrástica «ha de tener en lo sucesivo una luz» que tiene un claro sentido profético con futuro, algo que nos parece adecuado. En 1968 opta por el pasado perfecto, como si quisiera acentuar que se trata del hecho ya realizado sin lugar a dudas. Además, utiliza el adjetivo «jediné svetlo», es decir «única luz» en vez de «una luz», lo que refuerza el matiz ideológico de la expresión.

En cuanto a la última frase de la traducción, en las dos ediciones se mantiene una solución que no nos parece acertada. El protagonista de la novela navega en su lanza río abajo, «iluminado plenamente por el sol violento del mediodía» hacia su nueva vida, «dejando como una estela su grito de victoria» (Varela, 1967: 234-235). Oleríny (y también el traductor checo) sobreinterpreta la expresión y traduce «una estela» en 1951 como «ligotajúca sa hviezda», en 1968 como «žiarivá hviezda», es decir «estrella brillante / luminosa», aunque, según nuestra opinión, se trata -en este contexto- de la línea espumosa y blanca que dejaba la balsa sobre el agua del río. De ahí que la novela termine en eslovaco y checo con la clara alusión al símbolo de «la estrella luminosa».

\section{Conclusión}

Después del análisis comparativo de los dos textos hemos llegado a la conclusión de que la versión de la traducción eslovaca de $195^{1}$ presenta los rasgos típicos del idiolecto de un traductor principiante, además, en este caso recién llegado del extranjero. Se pueden percibir dificultades con el eslovaco coloquial, muchas expresiones se traducen con calcos. El traductor 
mantiene muchas referencias culturales y los elementos de las realia hispanoamericanas como exotismos sin transcripción, en estos casos no respeta la ortografía ni la gramática eslovacas. Por otro lado, las expresiones neutrales se traducen a menudo por dialectismos típicamente eslovacos, con rasgos específicos para la región de la Eslovaquia central, de donde proviene el traductor. La estructura de las construcciones morfológico-sintácticas se transpone literalmente, con participios, gerundios y otros elementos propios del español. Hay que decir que esto se debe no solamente a la poca experiencia de Vladimír Oleríny, sino también a la poca tradición de la traducción del español al eslovaco ${ }^{4}$.

En cuanto a la versión de 1968, es notable el cambio de la óptica traductora sobre todo respecto a la relación «lo otro/lo nuestro». Oleríny, ya como traductor experimentado, re-escribe su traducción según una perceptible estrategia traductora, que según nuestra opinión, falta en la primera versión. En este punto conviene mencionar que la década de los sesenta fueron los años del verdadero «boom» de las traducciones al eslovaco, algo que se refleja también en el desarrollo de la teoría de la traducción (Bakoš, Duurišin, Popovič), formulada «oficialmente» en los principios de la llamada «escuela eslovaca de traducción» publicados en 1984 (véase Ferenčík, 1982). Conforme con estos principios, se nota una clara tendencia hacia la actualización del vocabulario y naturalización de los elementos exóticos. Sin embargo, en este texto no figuran tantas expresiones dialectales eslovacas no adecuadas como en la primera edición. Por el contrario, se admiten varios retoques finos que podríamos considerar como «actualizaciones» ideológicas. El texto de la segunda edición contiene más referencias contextuales o sustituidas, o traducidas con explicaciones internas. La mayoría está transcrita ya según la ortografía eslovaca, se respeta más la estructura de las oraciones eslovacas. Es interesante, que muchas de estas expresiones formaban parte en 1951 del llamado «léxico sin equivalente». En los diálogos se usan expresiones más coloquiales, hay más fraseologismos y menos gerundios, construcciones nominales, pronombres posesivos y de advertencia. Hay menos notas a pie de página.

Finalmente podemos concluir, que la edición del 1951 es fruto del afán del traductor principiante culto y con talento. En 1968 la habilidad del traductor experimentado se nota también en su capacidad de considerar su obra a la

4 Hasta 1951 fueron traducidos del español al eslovaco 9 títulos de la literatura española y 4 de autores hispanoamericanos (tres de ellos argentinos). En 1968 contamos ya con 36 títulos traducidos de la literatura española y 11 de la literatura hispanoamericana. 
luz del nivel actual de la lengua meta y de la teoría coetánea de la traducción. Vladimír Oleríny no solamente corrige errores, insuficiencias o soluciones inadecuadas de su traducción, sino que además la re-escribe desde la perspectiva de su nuevo saber.

Cada época tiene sus maneras y estilo de traducir: el que impera en el momento en que le toca a vivir al traductor y que acompaña a la evolución de la lengua a la que se traduce. Las dos versiones analizadas y el carácter de los cambios que había sufrido su traducción «original» son buena prueba de que el factor temporal opera sin cesar y se reflejaría sin duda también en una tercera edición eslovaca de El río oscuro de Alfredo Varela.

\section{Bibliografía}

Amado, J. (1951): «Doslov». En: Alfredo Varela, Temná rieka. Bratislava: Dukla, 307-312.

Bílik, R. (1994): Industrializovaná literatúra (1945-1956). Bratislava: Proxy.

Bílik, R. (2008): Duch na ret'azi. (Sondy do literárnebo života na Slovensku v rokoch 1945-1989). Bratislava: Kalligram.

Ferenčík, J. (1982): Kontexty prekladu. Bratislava: Slovenský spisovatel'.

Hurtado Albir, A. (2010): «Las traducciones envejecen». En: N. Revista de Cultura: http://edant.revistaenie.clarin.com/notas/2010/05/19/_02197474.htm (20-11-2011).

Popovič, A. (1975): Teória umeleckébo prekladu. Bratislava: Tatran.

Povrazník, J. (1951): «Alfredo Varela: Temná rieka». En: Slovenské pobl'ady, 10, 660-662.

Uličný, M. (2005): Historia de las traducciones checas de literaturas de España e Hispanoamérica. Praha: Karolinum.

Varela, A. (1951): Temná rieka. Trad. Vladimír Oleríny. Bratislava: Dukla.

Varela, A. (1967): El Río oscuro. Buenos Aires: Centro Editor de América Latina.

Varela, A. (1968): Temná rieka. Trad. Vladimír Oleríny. Bratislava: Slovenské vydavatel'stvo politickej literatúry.

Varela, A. (1985): El Río oscuro. Buenos Aires: Hyspamerica Ediciones. 


\section{Eva Palkovičová}

Comenius University in Bratislava

\section{The time factor in two Slovak editions of the novel El río oscuro by Alfredo Varela}

Keywords: original, translation, time factor, re-edition

The aim of this study is to compare of two Slovak editions of the novel El rio oscuro by the Argentinian writer Alfredo Varela. This novel was first published in Slovak in 1951 as a translation by Vladimír Oleríny and in 1968 was republished in a new edition with significant changes to the translation. Since we are dealing with two different editions of the same translation published in the span of 17 years, it is interesting to examine the influence of the time factor on the translation itself, the edition, revision and re-edition of this literary work.

Following a comparative analysis of the two texts, we came to the conclusion that the edition from 1951 bears all hallmarks of a novice translator's idiolect, however it also reflects the short tradition of translating from Spanish into Slovak. In the 1968 edition there is a marked change in the translator's perspective, concerning, above all, the relation of 'the foreign' to 'the domestic'. There also is a clearer and pronounced translation strategy, reflecting the abilities of an experienced translator, the development of the target language and the development of the Slovak theory of translation. It seems to us that the influence of the time factor is visible in both editions examined and, it would with no doubt manifest in a possible third edition of Oleríny's translation, or, as the case may be, in another translation of Valera's El río oscuro. 


\section{Eva Palkovičová}

Univerza Komenskega v Bratislavi

\section{Časovni dejavnik v dveh slovaških izdajah romana El río oscuro Alfreda Varele}

Ključne besede: izvirnik, prevod, časovni dejavnik, ponatis

Avtorica v članku podrobno analizira dva slovaška prevoda romana El río oscuro (Temna reka) argentinskega pisatelja Alfreda Varele. Delo je v slovaščini prvič izšlo leta 1951, v prevodu Vladimírja Olerínyja. Leta 1968 je izšel drugi prevod, v katerega je isti prevajalec vnesel znatne spremembe. Ker gre za ponatis istega prevoda $\mathrm{v}$ razmiku sedemnajstih let, je zanimivo proučiti vpliv časovnega dejavnika na prevod, izdajo, ponovni pregled in ponatis knjige.

Avtorica po primerjalni analizi obeh besedil ugotavlja, da prevod iz leta 1951 vsebuje značilne elemente idiolekta prevajalca začetnika, odseva pa tudi kratko tradicijo prevajanja iz španščine v slovaščino. V izdaji iz leta 1968 se je spremenila prevajalska presoja, predvsem v odnosu »drugo : naše«. Opazna je tudi solidnejša prevajalska strategija, ki odseva spretnost izkušenega prevajalca, razvoj ciljnega jezika in teorije prevajanja na Slovaškem. Potrdi se, da je časovni dejavnik očiten $\mathrm{v}$ obeh analiziranih izdajah in da bi bil najverjetneje tudi v tretji izdaji tega romana - bodisi v različici Vladimírja Olerínyja bodisi $\mathrm{v}$ novem prevodu. 